\title{
Association of fatigue with an acute phase response in sarcoidosis
}

\author{
M. Drent*, R.M. Wirnsberger*, J. de Vries**, M.P. van Dieijen-Visser ${ }^{+}$, \\ E.F.M. Wouters*, A.M.W.J. Schols*
}

Association of fatigue with an acute phase response in sarcoidosis. M. Drent, R.M. Wirnsberger, J. de Vries, M.P. van Dieijen-Visser, E.F.M. Wouters, A.M.W.J. Schols. C)ERS Journals Ltd 1999.

ABSTRACT: The pathophysiological explanation for fatigue, one of the most common symptoms in sarcoidosis, still has to be elucidated. It was hypothesized that the presence of fatigue is associated with an acute phase response in sarcoidosis.

A cross-sectional study was performed in 38 sarcoidosis patients. Resting energy expenditure (REE) was measured in the fasting state by indirect calorimetry using a ventilated hood and adjusted for fat-free mass (FFM).

Patients with fatigue $(n=25)$ also suffered more frequently from other symptoms, such as exercise intolerance $(p=0.01)$, the need for sleep $(p=0.02)$ and weight loss $(p=$ $0.01)$, compared to those without fatigue $(n=13)$. However, no relationship was found between fatigue and serum angiotensin-converting enzyme (sACE) or lung function impairment. Patients with fatigue had higher levels of C-reactive protein (CRP) $\left(11.4 \pm 6.8 \mu \mathrm{g} \cdot \mathrm{mL}^{-1}, \mathbf{p}<0.0001\right)$ and REE adjusted for FFM $\left(33.0 \pm 3.7 \mathrm{kcal} \cdot \mathrm{kg} \mathrm{FFM}^{-1}\right.$, $\mathrm{p}<0.003)$ compared to those without fatigue $\left(3.2 \pm 2.2 \mathrm{mg} \cdot \mathrm{mL}^{-1} ; 29.2 \pm 2.8 \mathrm{kcal} \cdot \mathrm{kg} \mathrm{FFM}^{-1}\right)$, Furthermore, REE/FFM was significantly related to $C R P(r=0.54, p=0.001)$.

This study confirms the presence of an acute phase response as indicated by metabolic derangements and a moderate increase in C-reactive protein levels in sarcoidosis, particularly in those patients with constitutional symptoms. Future studies should focus on the clinical relevance and therapeutic implications of these findings. Eur Respir J 1999; 13: 718-722.
* Dept of Pulmonology, University Hospital Maastricht, Maastricht, the Netherlands. **Dept of Psychology, Tilburg University, The Netherlands. ${ }^{+}$Dept of Clinical Chemistry, University Hospital Maastricht, Maastricht, the Netherlands.

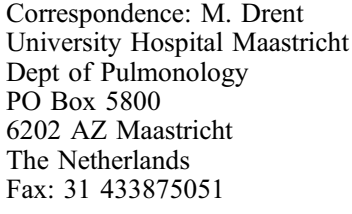

Keywords: Acute phase response C-reactive protein fatigue

metabolic derangement sarcoidosis

Received: June 301998

Accepted after revision September 221998
Sarcoidosis is a multiorgan disorder of unknown origin, characterized by T-lymphocyte and mononuclear phagocyte infiltration in the affected organs, granuloma formation, and distortion of the normal microarchitecture, which is probably antigen-driven [1]. The clinical manifestations of sarcoidosis are largely nonspecific, dependent on the intensity of the inflammation and organ systems affected, of which the lung is the most prominent. Patients with sarcoidosis generally present with symptoms directly related to the chest involvement such as coughing, dyspnoea, particularly with exertion, and chest pain. Furthermore, they may suffer from nonspecific constitutional complaints such as fever, weight loss, fatigue, anorexia and malaise [2].

While there is no single test that reflects accurately the progression of sarcoidosis, medical history, clinical examination, chest radiographs, lung function tests and serum angiotensin-converting enzyme (sACE) levels are used to evaluate and monitor the disease process [2-6]. When features of disease activity, for example radiological abnormalities, lung function impairment and SACE, become normal, less specific and otherwise difficult to objectify symptoms, such as fatigue and general weakness, may persist $[5,7]$. Previously, the authors found that sarcoidosis patients with normal lung function test results demonstrated reduced respiratory muscle strength and endurance time [8]. Correlations were found between these measures

For editorial comments see page 713. and the most commonly reported complaint, fatigue, in addition to impairment in health status. However, no such relation was demonstrated with sACE levels [8]. Pathognomonic criteria or a "gold standard" for monitoring the disease activity of sarcoidosis do not exist $[2,4,5]$. Therefore, a search for other parameters useful in monitoring disease activity is still of benefit.

Similar to systemic infections, extensive tissue damage owing to hypersensitivity or autoimmune reactions is capable of inducing an acute phase response [9]. This acute phase response is characterized by hypermetabolism and the elevation of acute phase proteins, such as C-reactive protein (CRP), which are produced in the liver $[9,10]$. Based on the fact that sarcoidosis can be considered an inflammatory disease together with observations in other inflammatory conditions, the authors hypothesized the presence of metabolic alterations and a hepatic acute phase response in sarcoidosis patients associated with constitutional symptoms such as fatigue. Furthermore, the impact of fatigue on clinical parameters used to assess disease activity in sarcoidosis was evaluated.

\section{Materials and methods}

\section{Subjects}

Thirty-eight outpatients with newly suspected untreated sarcoidosis were included in this study. The diagnosis of 
sarcoidosis was based on consistent clinical features, together with bronchoalveolar lavage (BAL) fluid analysis results [6]. Moreover, all patients had a biopsy confirmation of sarcoidosis. The clinical symptoms of the respective patients varied from none (sarcoidosis detected on routine chest radiography) to more or less severe respiratory symptoms or erythema nodosum and arthralgia (i.e. Löfgren's syndrome). None of the subjects participating had any significant medical history or comorbidity. Moreover, cutures of the BAL fluid samples obtained were all negative.

For information about the presence of constitutional symptoms, the participating patients completed a symptom questionnaire [11] under the supervision of a study assistant, to ensure correct answers and to avoid the omission of data. Moreover, the patient's quality of life (QoL) was evaluated using a broad-ranging QoL instrument, the World Health Organization QoL assessment instrument (WHOQoL-100; Dutch version) [12]. The WHOQoL-100 consists of 100 items assessing 24 facets of QoL within six domains and a global evaluative general QoL facet. To measure and qualify fatigue in the present study, only the energy and fatigue facet from the physical health domain was evaluated. Higher scores represent a better QoL for this facet [12]. Written informed consent was obtained from all subjects.

\section{Serological measurements}

At the time of the initial diagnosis, sACE and serum were assessed. ACE was measured with a colorimetric method using a test kit from Fujirebio Inc. (Tokyo, Japan). sACE acts upon the substrate $p$-hydroxybenzoyl-glycyl-Lhistidyl-L-leucine and separates $p$-hydroxybenzoyl-glycine. Hippuricase reacts with and breaks down p-hydroxybenzoyl-glycine into $p$-hydroxybenzoic acid and glycine. Quinoneimine dye is produced by oxidation and condensation of the $p$-hydroxybenzoic acid and 4-aminoantipyrine using sodium metaperiodate $\left(\mathrm{NaIO}_{4}\right)$. Finally, the concentration of quinoneimine dye is quantitatively measured at its maximum absorbance of $505 \mathrm{~nm}$ to evaluate the activity of ACE. The reference normal range under this test method is $9-25 \mathrm{U} \cdot \mathrm{L}^{-1}$.

CRP was measured using a turbidimetric method performed using the Beckman synchron CX-7 system (kit 465231; Mijdrecht, the Netherlands). In this test, CRP combines with a specific antibody to form insoluble antigen-antibody complexes. The detection limit for CRP using the turbimetry assay was $2 \mu \mathrm{g} \cdot \mathrm{mL}^{-1}$, with a normal range of $2-9 \mu \mathrm{g} \cdot \mathrm{mL}^{-1}$.

\section{Lung function tests and respiratory muscle strength}

Lung function measurements included forced expiratory volume in one second (FEV1) and inspiratory vital capacity (IVC) measured with a pneumotachograph. The transfer factor of the lung for carbon monoxide $(T \mathrm{~L}, \mathrm{CO})$ was measured by the single-breath method (Masterlab; Jaeger, Würzburg, Germany). Values were expressed as a percentage of those predicted [13].

Inspiratory and expiratory muscle strength were assessed by measuring maximal respiratory mouth pressures using the method of BLACK and HyATT [14]. The maximal inspiratory mouth pressure $\left(P_{\mathrm{I}, \mathrm{max}}\right)$ was measured at residual volume $(\mathrm{RV})$, and the maximal expiratory mouth pressure $(P E, \max )$ was measured at total lung capacity (TLC). The equipment used was a pressure transducer (model MP 45-30; Validyne Engineering Corp., Northridge, CA, USA). All signals were recorded on a strip chart (type BD 31; Kipp \& Zonen, Delft, the Netherlands). A needle was placed in the proximal end of the mouthpiece to ensure that efforts were performed with an open glottis. At least five manoeuvres were performed, until the three highest values were within $5 \%$ of each other. All subjects were seated in an upright position and were wearing a noseclip while performing the tests, and the same instructions were given to each subject by an investigator. Values are expressed as absolute values and as percentages of predicted values according to WILSON et al. [15].

\section{Chest radiographs}

Chest radiographs were performed in the posterioranterior and lateral projections, and were classified by a single experienced reader, blinded to the patient's clinical history, in a standard manner according to the radiographic stage (0-IV) [16].

\section{Metabolic measures}

Body composition was measured by single-frequency bioelectrical impedance analysis (RJL Systems, Detroit, MI, USA) in the supine position on the right side. Fat-free mass (FFM) was calculated from height ${ }^{2} /$ resistance and body weight using the Lukaski formula. In order to assess the degree of functional tissue depletion, FFM was adjusted for body size by calculating the FFM index (FFM/ height $\left.^{2}\left(\mathrm{~kg} \cdot \mathrm{m}^{-2}\right)\right)$. Fat mass was calculated by subtracting FFM from body weight.

Resting energy expenditure (REE) was measured after an overnight fast under standardized conditions [17] by means of indirect calorimetry using a ventilated hood (Oxycon beta $\AA$, Mijnhardt, Bunnik, the Netherlands). REE was adjusted for FFM and sex by analysis of covariance [18].

\section{Statistical analysis}

Results are presented as mean \pm SD unless stated otherwise. Pearson's and, if appropriate, partial (sex was partialled out) correlation coefficients (r) were computed to assess the mutual relationship between the various tests. The Chisquared test was used for nominal variables. To assess sex differences between the studied groups, Student's t-test was used. To examine differences between the sarcoidosis groups with and without fatigue with respect to medical data, an analysis of variance was applied with sex as covariate. Analyses of variance (sex as covariate) were also used to compare patients with and without exercise intolerance and patients with and without weight loss with regard to REE adjusted for FFM. In all tests, a p-value of $<0.05$ was considered to be statistically significant. All analyses were performed using the Statistical Package for Social Science (SSPS) for Windows (SPSS, Chicago, IL, USA). 


\section{Results}

The demographic and clinical characteristics, laboratory test results, lung function test results, and body composition of the patients suffering from sarcoidosis studied $(\mathrm{n}=38)$ are summarized in table 1 . The patient population was divided into two groups, according to the presence of fatigue as assessed by WHOQoL-100. Group I $(n=13)$ consisted of patients who did not suffer from fatigue while group II $(\mathrm{n}=25)$ consisted of sarcoidosis patients who suffered from fatigue. Both groups differed with respect to other constitutional symptoms as well (fig. 1). Patients with fatigue suffered more frequent dyspnoea $\left(\chi^{2}(1)=6.3, p=0.01\right)$, exercise intolerance $\left(\chi^{2}(1)=6.9, p=\right.$ $0.009)$, muscle pain $\left(\chi^{2}(1)=10.2, \mathrm{p}=0.001\right)$, eye problems $\left(\chi^{2}(1)=4.1, p=0.04\right)$ and the need for sleep $\left(\chi^{2}(1)=3.9\right.$,

Table 1. - Summary of demographic, clinical, laboratory and lung function test results, as well as metabolic characteristics of the patients with sarcoidosis

\begin{tabular}{|c|c|c|c|}
\hline & Group I & Group II & $\begin{array}{c}\text { Total } \\
\text { population }\end{array}$ \\
\hline \multicolumn{4}{|c|}{ Demographic, clinical and laboratory characteristics } \\
\hline $\mathrm{n}$ & 13 & 25 & 38 \\
\hline Sex M/F & $8 / 5$ & $14 / 11$ & $22 / 16$ \\
\hline Age yrs & $40.2 \pm 10.7$ & $40.0 \pm 12.1$ & $40.1 \pm 11.5$ \\
\hline Smoking yes/no & $3 / 10$ & $4 / 21$ & $7 / 31$ \\
\hline \multicolumn{4}{|l|}{ Radiographic stage } \\
\hline 0 & 1 & 1 & 2 \\
\hline I & 4 & 7 & 11 \\
\hline II & 8 & 10 & 18 \\
\hline III & 0 & 6 & 6 \\
\hline IV & 0 & 1 & 1 \\
\hline Calcium $\mathrm{mmol} \cdot \mathrm{L}^{-1}$ & $2.47 \pm 0.07$ & $2.43 \pm 0.08$ & $2.44 \pm 0.08$ \\
\hline $\mathrm{CRP} \mu \mathrm{g} \cdot \mathrm{mL}^{-1}$ & $3.2 \pm 2.2$ & $11.4 \pm 6.8 * *$ & $8.7 \pm 6.9$ \\
\hline SACE U.L $\mathrm{L}^{-1}$ & $24.9 \pm 9.8$ & $26.1 \pm 11.5$ & $25.7 \pm 10.8$ \\
\hline $\mathrm{ESR} \mathrm{mm} \cdot \mathrm{h}^{-1}$ & $6.8 \pm 10.0$ & $12.1 \pm 10.7$ & $10.3 \pm 10.7$ \\
\hline \multicolumn{4}{|c|}{ Lung function test results } \\
\hline FEV1\% pred & $85.6 \pm 20.9$ & $88.3 \pm 18.4$ & $87.4 \pm 19.1$ \\
\hline $\mathrm{FVC} \%$ pred & $100.6 \pm 23.8$ & $92.7 \pm 21.9$ & $95.5 \pm 22.6$ \\
\hline$T \mathrm{~L}, \mathrm{CO} \%$ pred & $89.1 \pm 22.4$ & $87.8 \pm 21.7$ & $88.2 \pm 21.6$ \\
\hline$P \mathrm{I}, \max \mathrm{cmH}_{2} \mathrm{O}$ & $-113.0 \pm 23.3$ & $-91.2 \pm 25.1 *$ & $-97.8 \pm 26.3$ \\
\hline$P \mathrm{E}, \max \mathrm{cmH}_{2} \mathrm{O}$ & $117.4 \pm 26.6$ & $100.0 \pm 22.3^{*}$ & $105.3 \pm 24.6$ \\
\hline \multicolumn{4}{|c|}{ Metabolic characteristics } \\
\hline $\mathrm{BMI} \mathrm{kg} \cdot \mathrm{m}^{-2}$ & $24.0 \pm 2.5$ & $26.0 \pm 3.5^{+}$ & $25.4 \pm 3.3$ \\
\hline FFM kg & $56.0 \pm 9.5$ & $52.6 \pm 11.1$ & $53.8 \pm 10.6$ \\
\hline $\mathrm{FFM}$ index $\mathrm{kg} \cdot \mathrm{m}^{-2}$ & $18.0 \pm 1.9$ & $17.2 \pm 2.8$ & $17.5 \pm 2.5$ \\
\hline FFM \% weight & $75.4 \pm 5.1$ & $66.6 \pm 8.6^{* *}$ & $69.5 \pm 8.6$ \\
\hline Fat mass $\mathrm{kg}$ & $18.1 \pm 3.8$ & $25.9 \pm 8.1 *$ & $23.2 \pm 7.8$ \\
\hline Fat mass $\%$ weight & $24.6 \pm 5.1$ & $33.5 \pm 8.4 * *$ & $30.7 \pm 8.5$ \\
\hline REE kcal $\cdot 24 \mathrm{~h}^{-1}$ & $1635 \pm 309$ & $1712 \pm 252^{+}$ & $1687 \pm 270$ \\
\hline 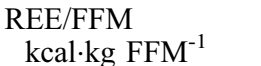 & $29.2 \pm 2.8$ & $33.0 \pm 3.7 * *$ & $31.8 \pm 3.9$ \\
\hline
\end{tabular}

Data are expressed as number or mean \pm SD. Group I: patients presenting without fatigue; and group II: patients suffering from fatigue. M: male; F: female; CRP: C-reactive protein (reference range $\left.2-9 \mu \mathrm{g} \cdot \mathrm{mL}^{-1}\right)$; sACE: serum angiotensin-converting enzyme (reference range 9-25 U.L ${ }^{-1}$ ); ESR: erythrocyte sedimentation rate (reference range $0-12 \mathrm{~mm} \cdot \mathrm{h}^{-1}$ ); FEV1: forced expiratory volume in one second; FVC: forced vital capacity; $T \mathrm{~L}, \mathrm{CO}$ : transfer factor of the lung for carbon monoxide; $P \mathrm{I}$,max: maximal inspiratory mouth pressure measured at residual volume; $P \mathrm{E}$,max: maximal expiratory mouth pressure measured at total lung capacity; BMI; body mass index; FFM: fat-free mass; REE: resting energy expenditure; Reference range for calcium 2.1-2.6 mmol. $\mathrm{L}^{-1}{ }^{+}: \mathrm{p}=0.05 ; *: \mathrm{p}<0.05 ; * *: \mathrm{p}<0.01$.

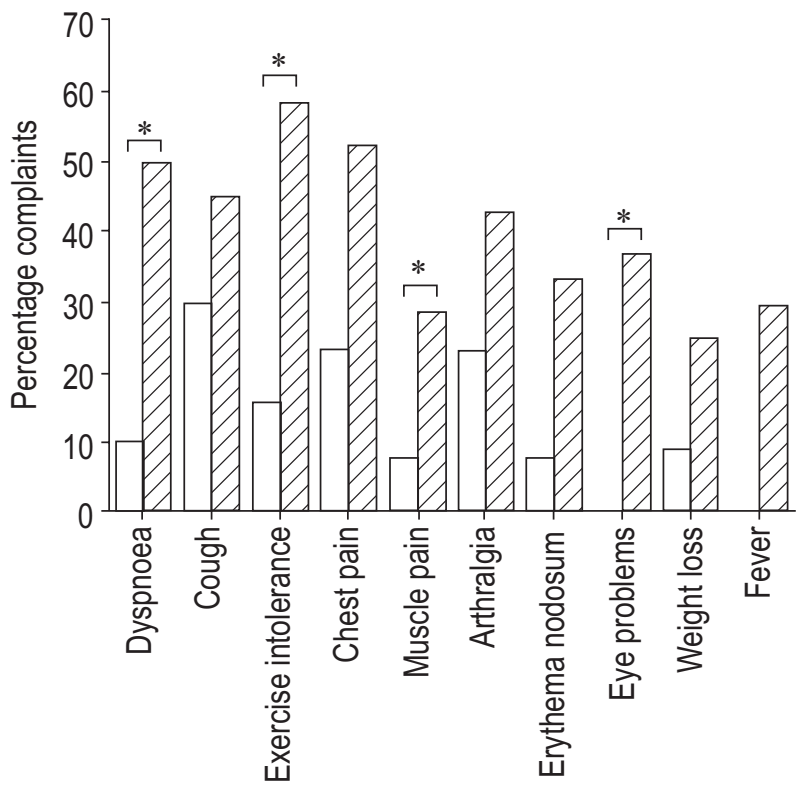

Fig. 1. - Most relevant reported symptoms in sarcoidosis. Group I ( $\square$, $\mathrm{n}=13)$ : patients without fatigue, and group II $(\mathbb{Z}, \mathrm{n}=25)$ : patients suffering from fatigue. ${ }^{*}: \mathrm{p}<0.05$ group I versus group II.

$p=0.05)$ compared to patients without fatigue. These respective groups did not differ with respect to age, smoking history, use of corticosteroids, radiographic stage, sACE levels or lung function test results.

Group II patients, with fatigue, reported more weight loss (number of $\mathrm{kg}, \mathrm{F}(1)=7.9, \mathrm{p}=0.02$ ), had a higher serum CRP level compared to group I $(\mathrm{F}(1)=15.4, \mathrm{p}<0.0001)$, a higher $\operatorname{REE}(\mathrm{F}(1)=4.3, \mathrm{p}=0.05)$, a higher $\mathrm{REE}$ adjusted for FFM $(F(1)=9.5, p=0.004)$ as well as fat mass expressed as a percentage of weight $(\mathrm{F}(1)=13.4, \mathrm{p}=0.001)$ and body mass index $(\mathrm{BMI})(\mathrm{F}(1)=4.1, \mathrm{p}=0.05)$ (table 1). No difference was demonstrated in FFM. However, FFM calculated as a percentage of body weight was lower in the group with fatigue $(\mathrm{F}(1)=10.5, \mathrm{p}=0.0003)$. Furthermore, the $P \mathrm{I}$,max $(\mathrm{F}(1)=5.4, \mathrm{p}=0.04)$ appeared to be more impaired in group II. Moreover, REE divided by FFM was significantly associated with CRP levels $(r=0.54, p=0.001$; fig. 2), and significantly higher in patients suffering from weight loss $(\mathrm{F}(1)=5.2, \mathrm{p}=0.03)$ or exercise intolerance $(\mathrm{F}(1)=12.3, \mathrm{p}=0.001)$. Exercise intolerance also appeared to be related to increased body temperature $\left(\chi^{2}(1)=5.7\right.$, $\mathrm{p}=0.02)$. The radiographic stage was positively related to REE divided by FFM ( $\mathrm{r}=0.39, \mathrm{p}=0.02)$. However, no relationship was found between either the radiographic stage and lung-function test results or with sACE or any other laboratory finding listed in table 1 .

\section{Discussion}

This study is the first to describe a relationship between one of the most common symptoms in sarcoidosis, i.e. fatigue and the presence of an acute phase response, evidenced by hypermetabolism and a limited increase in the serum CRP level. Moreover, patients suffering from fatigue were characterized by a different body composition compared to those patients not suffering from fatigue. No relationship was found between fatigue and commonly 


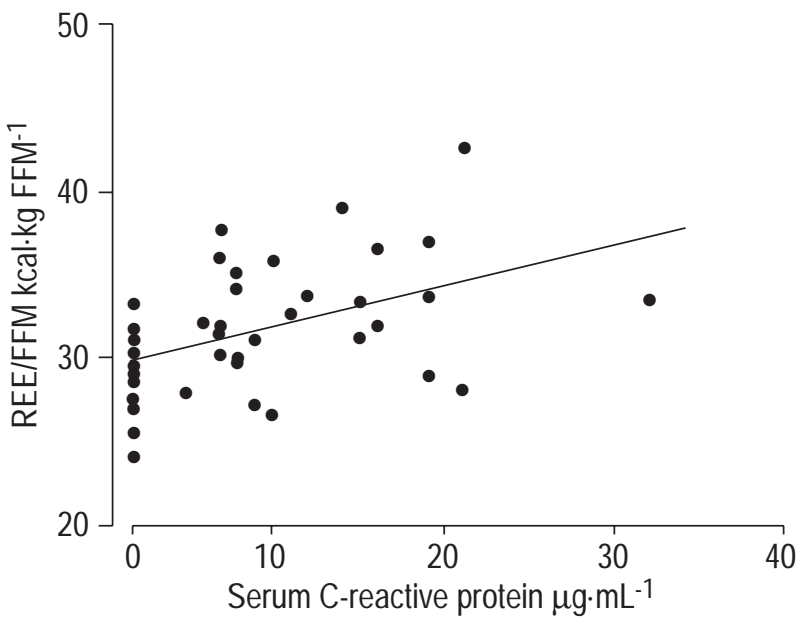

Fig. 2. - Relationship between resting energy expenditure (REE) in kcal adjusted for the fat free mass (FFM; $\mathrm{kg}$ ) and C-reactive protein $(\mathrm{r}=0.54, \mathrm{p}=0.001)$.

used parameters for monitoring disease activity in sarcoidosis, such as the sACE level, radiographic findings and lung function tests. Only a negative relationship between the radiographic stage and the FFM was demonstrated. Clearly, there is a wide spectrum of tissue inflammation and organ dysfunction within, as well as between, each radiographic stage. KARETZKY and MCDONOUGH [19] found that the magnitude of functional impairment may vary widely from the apparent histopathological involvement, as reflected by chest radiography results and lung volumes. There is little true incidence data in the literature regarding metabolic alterations in patients with sarcoidosis. Only one report, including 12 patients within various interstitial lung diseases (ILD), of which only three were suffering from sarcoidosis, demonstrated the presence of an elevated REE [20].

Increased CRP production is a nonspecific response to most forms of tissue inflammation [21, 22]. Hepatocytes have been identified as the site of origin of acute phase proteins such as CRP. Thus, the liver plays an important role in the acute phase response $[10,23]$. The CRP response (although rather minor) was present in the majority of patients and appeared indicative of the inflammatory activity of sarcoidosis. Similar responses (resulting in a slightly elevated or normal CRP) are reported in inflammatory disorders such as systemic lupus erythematosus, Crohn's disease, and ulcerative colitis [24]. In contrast, an intercurrent microbial infection provokes a major CRP response [10]. To date, Hind et al. [25] have found, in their study population, an increased CRP in two of nine patients with active sarcoidosis $(22.2 \%)$, but in none of five inactive sarcoidosis patients.

Most clinical manifestations of sarcoidosis are secondary to the direct effect of the accumulation of activated immunocompetent cells in the tissues involved, notably helper T-lymphocytes and macrophages [1, 2, 5, 9, 26, 27]. The activation of cells of the monocyte/macrophage lineage is compartmentalized. Alveolar macrophages have been identified as releasing tumour necrosis factor (TNF)- $\alpha$, interleukin (IL)-1, and prostaglandin $\mathrm{E}_{2}$ spontaneously in the course of sarcoidosis, whereas the corresponding cells of the peripheral blood are quiescent $[1,5,26]$. In the present study, cytokine levels were not measured but, as would be expected, a significant relationship between the elevated CRP levels and resting metabolic rate was found. The clinical significance of this relationship was indicated by the fact that REE and CRP were significantly higher in patients suffering from fatigue. In line with this, the authors have previously found that the serum CRP level was related to fatigue in patients with an autoimmune disease, rheumatoid arthritis (RA). Patients suffering from RA with a high serum CRP level were reported to be significantly more impaired by fatigue (assessed by the WHOQoL-100 facet energy and fatigue [12]) compared to those with a normal serum CRP level (unpublished data). In some hypermetabolic patients with chronic obstructive pulmonary disease [17], an increased resting metabolic rate seems to be related to the level of systemic inflammation. Furthermore, patients with fatigue were characterized by a significantly higher fat mass, whereas FFM as a percentage of body weight was significantly decreased in this group. These body compositional changes suggest a preferential loss of FFM in the latter group. The findings of the present study could indicate a catabolic response in a subgroup of sarcoidosis patients, which may be consistent with the hypothesis that during an acute phase response cytokines redirect host protein metabolism away from peripheral tissue such as muscle and towards the liver. The higher fat mass in the subgroup of sarcoidosis patients suffering from fatigue, however, could in view of other symptoms experienced also be associated with a disease-related impairment of the functional capacity [26, 28]. Moreover, under those circumstances, one might also expect a higher body weight and perhaps weight gain in the patients with symptoms, whereas, on the contrary, weight loss was reported more often. Nevertheless, a decreased FFM in turn may affect respiratory muscle strength, which, in the present study as well as in a previous study, was indeed found to be significantly reduced [8]. Furthermore, it was previously reported that patients with sarcoidosis were limited in physical functioning [8].

It has generally been assumed that the marked loss of body proteins resulting in a loss of body mass (initiated by TNF- $\alpha$ and leukocyte pyrogen or IL- 1 and mediated by prostaglandin $\mathrm{E}_{2}$ ) occurs primarily in the skeletal muscle, which constitutes the major protein reserve of the organism [23]. Net protein breakdown in muscle can also provide amino acids for synthesis of acute phase proteins by the liver and for the synthesis of immunoglobulins, commonly increased in sarcoidosis [2, 4, 23]. Leukocyte pyrogen also causes induction of acute phase proteins and enhancement of lymphocyte proliferation [23, 26]. Moreover, it is well established that prostaglandin $\mathrm{E}_{2}$ is a very potent stimulator of peripheral pain receptors and hyperalgia [23]. In immune disorders such as sarcoidosis and RA, immunederived cytokines initiate an acute phase response, which is also characterized by fever, inactivity, muscle pain, fatigue, anorexia, and catabolism [23, 29, 30]. An appreciation of the processes of the acute phase reaction is likely to be of clinical relevance. For example, the recent demonstration that muscle breakdown, like fever, is brought about by IL-1 via an intermediate prostaglandin step, suggests that antiprostaglandin agents may not only cause defervescence but might also help to prevent muscle breakdown [10]. Therefore, administration of nonsteroidal anti-inflammatory drugs, as an alternative to steroids, might be of benefit 
in the treatment of sarcoidosis as it has been suggested that these drugs decrease rates of muscle proteolysis [3, 5, 23]. Future studies are needed to evaluate this suggestion.

In conclusion, this study indicates that an acute phase response, as evidenced by metabolic derangements and a moderate increase in the serum C-reactive protein level, is involved in sarcoidosis. The resting energy expenditure and serum C-reactive protein level appeared to quantify and characterize the constitutional impairment and inflammation in patients with sarcoidosis. In addition, constitutional symptoms, e.g. fatigue, that are otherwise difficult to objectify accurately, were found to be related to the resting energy expenditure as well as the serum C-reactive protein level. Therefore, an assessment of the serum C-reactive protein level and resting energy expenditure adjusted for body composition may be useful in the management of sarcoidosis. Further investigations, including cytokine determination, are needed to determine the clinical importance of the acute phase response associated with inflammation and related symptoms, such as fatigue, in sarcoidosis.

\begin{abstract}
Acknowledgements. The authors would like to thank H. Voets, A. de Vries and G. Pronk for their great help in collecting the data, as well as M. Elfferich for her advice during the preparation of this manuscript
\end{abstract}

\section{References}

1. Müller-Quernheim J. Sarcoidosis: immunopathogenetic concepts and their clinical appreciation. Eur Respir $J$ 1998; 11: 716-738.

2. Sharma OP, Alam S. Diagnosis, pathogenesis and treatment of sarcoidosis. Curr Opin Pulm Med 1995; 1: 392400.

3. Hunninghake GW, Gilbert S, Pueringer R, et al. Outcome of the treatment of sarcoidosis. Am J Respir Crit Care Med 1994; 149: 893-898.

4. World Association of Sarcoidosis and other Granulomatous Disorders. Consensus conference: activity of sarcoidosis. Eur Respir J 1994; 7: 624-627.

5. Mü1ler-Quernheim J. The cytokine network in sarcoidosis. Eur Cytokine Netw 1996; 7: 13-26.

6. Drent M, Nierop van MAMF, Gerritsen FA, Wouters EFM, Mulder PGH. Computer program using BALF analysis results as diagnostic tool in interstitial lung diseases. Am J Respir Crit Care Med 1996; 153: 736-741.

7. James DG. Complications of sarcoidosis. Chronic fatigue syndrome. Sarcoidosis 1993; 10: 1-3.

8. Wirnsberger RM, Drent M, Hekelaar N, et al. Relationship between respiratory muscle function and quality of life in sarcoidosis. Eur Respir J 1997; 10: 1450-1455.

9. Anisman H, Baines MG, Berczi I, et al. Neuroimmune mechanisms in health and disease: 2. Disease. Can Med Assoc J 1996; 155: 1075-1082.

10. Highton J. The acute phase response: a clinical perspective. Aust NZ J Med 1984; 14: 173-178.

11. Wirnsberger RM, Vries de J, Wouters EFM, Drent M. Clinical presentation of sarcoidosis in the Netherlands. An epidemiological study. Neth J Med 1998; 53: 53-60.

12. Wirnsberger RM, Vries de J, Breteler MHM, Heck van GL, Wouters EFM, Drent M. Evaluation of quality of life in sarcoidosis patients. Respir Med 1998; 92: 750-756.
13. Quanjer PH, Tammeling GJ, Cotes JE, Pederson OF, Peslin R, Yernault J-C. Lung volumes and forced ventilatory flows. Report working party standardization of lung function tests. European Commission for Steel and Coal. Official statement of the European Respiratory Society. Eur Respir J 1993; 6: Suppl. 16, 5-40.

14. Black LF, Hyatt RE. Maximal respiratory pressures: normal values and relationship to age and sex. Am Rev Respir Dis 1969; 99: 696-702.

15. Wilson SH, Cooke NT, Edwards RHT, Spiro SG. Predicted normal values for maximal respiratory pressures in Caucasian adults and children. Thorax 1984; 39: 535-538.

16. DeRemee RA. The roentgenographic staging of sarcoidosis. Chest 1983; 83: 128-133.

17. Schols AMWJ, Buurman WA, Staal-van den Brekel AJ, Dentener MA, Wouters EFM. Evidence for a relation between metabolic derangements and increased levels of inflammatory mediators in a subgroup of patients with obstructive pulmonary disease. Thorax 1996; 51: 819-824.

18. Ravussin E, Bogardus C. Relationship of genetics, age and physical fitness to daily energy expenditure and fuel utilization. Am J Clin Nutr 1989; 49: 968-975.

19. Karetzky M, McDonough M. Exercise and resting pulmonary function in sarcoidosis. Sarcoidosis 1996; 13: 43-49.

20. Fitting JW, Frascarolo P, Jéquier E, Leuenberger P. Resting energy expenditure in interstitial lung disease. $\mathrm{Am}$ Rev Respir Dis 1990; 142: 631-635.

21. Hrycaj P, Wurm K, Mennet P, Müller W. Microheterogenity of acute-phase glycoproteins in patients with pulmonary sarcoidosis. Eur Respir $J$ 1996; 9: 313-318.

22. Asano M, Minagawa T, Ohmichi M, Hiraga Y. Detection of endogenous cytokines in sera or in lymph nodes obtained from patients with sarcoidosis. Clin Exp Immunol 1991; 84: 92-96.

23. Baracos V, Rodemann HP, Dinarello CA, Goldberg AL. Stimulation of muscle protein degradation and prostaglandin $E_{2}$ release by leukocytic pyrogen (interleukin1). A mechanism for the increased degradation of muscle proteins during fever. N Engl J Med 1983; 308: 553-558.

24. Fagan EA, Dyck RF, Maton PN, et al. Serum levels of Creactive protein in Crohn's disease and ulcerative colitis. Eur J Clin Invest 1982; 12: 351-359.

25. Hind CR, Flint KC, Hudspith BN, Felmingham D, Brostoff J, Johnson NM. Serum C-reactive protein concentrations in patients with pulmonary sarcoidosis. Thorax 1987; 42: 332-335.

26. De Rose V, Trentin L, Crivellari MT, et al. Release of prostaglandin $\mathrm{E}_{2}$ and leukotriene $\mathrm{B}_{4}$ by alveolar macrophages from patients with sarcoidosis. Thorax 1997; 52: 76-83.

27. Drent M, Veizen-Blad van H, Diamant M, Hoogsteden HC, Bosch van den JMM. Relationship between disease presentation of sarcoidosis and $\mathrm{T}$ lymphocyte profile: a study in bronchoalveolar lavage fluid. Chest 1993; 104: 795-800.

28. Evans WJ, Campbell WW. Sarcopenia and age-related changes in body composition and functional capacity. $J$ Nutr 1993; 123: 465-468.

29. Landay AL, Jessop C, Lennette ET, Levy JA. Chronic fatigue syndrome: clinical condition associated with immune activation. Lancet 1991; 338: 707-712.

30. Voijdani A, Ghoneum M, Choppa PC, Magtoto L, Lapp $\mathrm{CW}$. Elevated apoptotic cell population in patients with chronic fatigue syndrome: the pivotal role of protein kinase RNA. J Intern Med 1997; 242: 465-478. 